\title{
Ultrastructure and Neuronal Control of Luminous Cells in the Copepod Gaussia princeps
}

\author{
MARK R. BOWLBY ${ }^{1}$ AND JAMES F. CASE \\ Marine Science Institute and Department of Biological Sciences, \\ University of California, Santa Barbara, California 93106
}

\begin{abstract}
The physiology of light production in copepods is largely unknown. The mesopelagic copepod Gaussia princeps possesses luminous glands, each consisting of a single large cell discharging through a cuticular pore. Slow flashes external to the cuticle are triggered from excised abdomens by electrical stimulation of the ventral nerve cord. Each luminous cell contains UV fluorescent secretory vesicles distally, which are secreted through a valved cuticular pore. Each luminous cell, except for the most proximal portion, is surrounded by a cellular sheath, which appears to form the distal valve. Luminous cells have a stem containing small, electron-lucent precursors to secretory vesicles proximal to the fluorescent vesicles. Nerve terminals, filled with large synaptic vesicles, are associated with the unsheathed proximal cell membrane. Gap junctions interconnect the nerve terminals, and possibly serve to accelerate conduction to the luminous cell to achieve a synchronous effector output.
\end{abstract}

\section{Introduction}

Many marine copepods produce brilliant luminous secretions. Despite many investigations (Barnes and Case, 1972; Herring, 1988; Bannister and Herring, 1989; Latz et al., 1990), much remains to be understood about the physiology of light production.

Copepod luminescence was first thought to involve the expulsion of luciferin and luciferase from separate glands through a common pore, with mixing and light emission occurring externally to the cuticle (Clarke et al., 1962). Recent studies, however, refute this theory (Herring, 1988; Bannister and Herring, 1989; Bowlby and Case, 1989),

Received 21 December 1990; accepted 8 March 1991

${ }^{1}$ Present address: Department of Neurobiology, Harvard Medical School, 220 Longwood Ave., Boston, MA 02115. as does this investigation. Individual light glands in some Metridinidae consist of a single cell type occurring in a unitary relationship with cuticular pores (Herring, 1988; Bannister and Herring, 1989). There is little evidence, other than in some ostracods, for the separate cellular packaging of luciferin and luciferase in any luminous organism (Harvey, 1952).

Control of luminous glands in copepods has not previously been investigated, although the short latency between stimulus and light emission indicates a probable nervous involvement (Barnes and Case, 1972; Latz et al., 1987, 1990). Many other organisms, such as crustaceans (Dennell, 1940), teleost fish (Nicol, 1967; Baguet and Case, 1971; Anctil and Case, 1977), fireflies (Buck and Case, 1961; Case and Buck, 1963; Smith, 1963; Linberg and Case, 1982), coelenterates (Anderson and Case, 1975; Bassot et al., 1978), and annelids (Herrera, 1977), possess demonstrated or suspected ncuronal control pathways of luminous glands (reviewed by Case and Strause, 1978). Experiments on euphausiids suggest that serotonin may be involved in neurotransmission to the photophores (Kay, 1965, 1966). The ophiuroids have undergone an extreme specialization of generating and propagating luminescence within modified nerve cells of the radial nerve cord (Brehm, 1977).

I uminous cells in copepods fluoresce when excited with ultraviolet (UV) light (Barnes and Case, 1972; Herring, 1988; Bannister and Herring, 1989), due to absorption by luciferin and subsequent re-emission in the visible region of the spectrum. This technique, in conjunction with image intensification of luminous sites, has allowed identification of at least 14 luminous sites on the antennae, cephalothorax, thorax, mandibular palps, and urosome of G. princeps (Clarke et al., 1962; Barnes and Case, 1972; Bannister and Herring, 1989; Bowlby and Case, in press), along with a similar distribution of sites in Pleuromamma 
xiphias and Metridia princeps (Bannister and Herring, 1989).

The mesopelagic calanoid copepod $G$. princeps (T. Scott) occurs below $400 \mathrm{~m}$ during the day, and vertically migrates to an upper limit of $200 \mathrm{~m}$ at night. They occur in numbers up to approximately 25 individuals $\cdot 1000 \mathrm{~m}^{-3}$ (Childress, 1977).

In this investigation, the physiology of light production was studied in the mesopelagic copepod Gaussia princeps. Light, scanning, and transmission electron microscopy were used to elucidate luminous cell ultrastructure and associated neuroeffector junctions. This may ultimately lead to a more complete understanding of the adaptive significance bioluminescence serves in the midwater environment.

\section{Materials and Methods}

\section{Specimen collection}

Adult male and female specimens of Gaussia princeps (T. Scott) (mean total body length $1 \mathrm{~cm}$ ) were collected from 1986 through 1989 from the San Clemente Basin, off the coast of California, at approximately $32^{\circ} \mathrm{N}, 117^{\circ} \mathrm{W}$. Collections were made from the R. V. New Horizon and R. V. Point Sur, with an opening-closing Tucker trawl (length, $30 \mathrm{~m}$; mouth, $10 \mathrm{~m}^{2}$ ). The trawl was equipped with an insulated cod end (Childress et al., 1978), and towed between 400 and $800 \mathrm{~m}$ depth. Specimens were sorted and maintained in filtered seawater at $6^{\circ} \mathrm{C}$ until testing. Animals were fed Artemia nauplii or an unsorted zooplankton/phytoplankton mixture, collected locally at $10 \mathrm{~m}$ depth, twice per week. Individuals survived for up to 6 months in this regime.

\section{Physiological experiments}

Adult Gaussia princeps were anesthetized with 2-phenoxyethanol and held non-invasively, using fine U-shaped pins, in a Sylgard-lined petri dish filled with chilled seawater. Specimens remained dark and undisturbed for 4 $\mathrm{h}$, to allow recovery from the anesthetic and partial restoration of bioluminescent reserves. The abdomen was subsequently isolated by bisection at abdominal segment 1 (A1), and used for all subsequent trials. Secondary longitudinal incisions were often performed, to permit localized stimulation of different tissues. Bioluminescence was elicited with single 10-70 V square wave pulses of 1$100 \mathrm{~ms}$ duration, using a 5 to $10 \mathrm{Mohm}$ resistance tungsten microelectrode and an indifferent bath electrode. Luminescence was recorded with a photomultiplier tube (PMT) with a $5 \mathrm{~mm}$ diameter input fiber optic attached to a micromanipulator. The PMT signal was recorded and stored on a Nicolet digital oscilloscope. Radiometric calibration was not performed, owing to the variable input geometry of the manipulated fiber optic.

\section{Microscopy}

Epifluorescence microscopy was conducted on intact specimens and excised abdominal tissue from 20 anesthetized specimens using ultraviolet light from a mercury lamp filtered with $365 \mathrm{~nm}$ excitation, $395 \mathrm{~nm}$ dichroic, and $420 \mathrm{~nm}$ barrier filters. Ultraviolet and broadband visible light were separately or simultaneously used.

Primary fixation for light microscopy, transmission electron microscopy (TEM), and scanning electron microscopy (SEM) was done in $1 \%$ paraformaldehyde and $3 \%$ glutaraldehyde in $0.2 \mathrm{M}$ sodium phosphate buffer with $5 \%$ glucose. Secondary fixation was carried out in $2 \% \mathrm{OsO}_{4}$
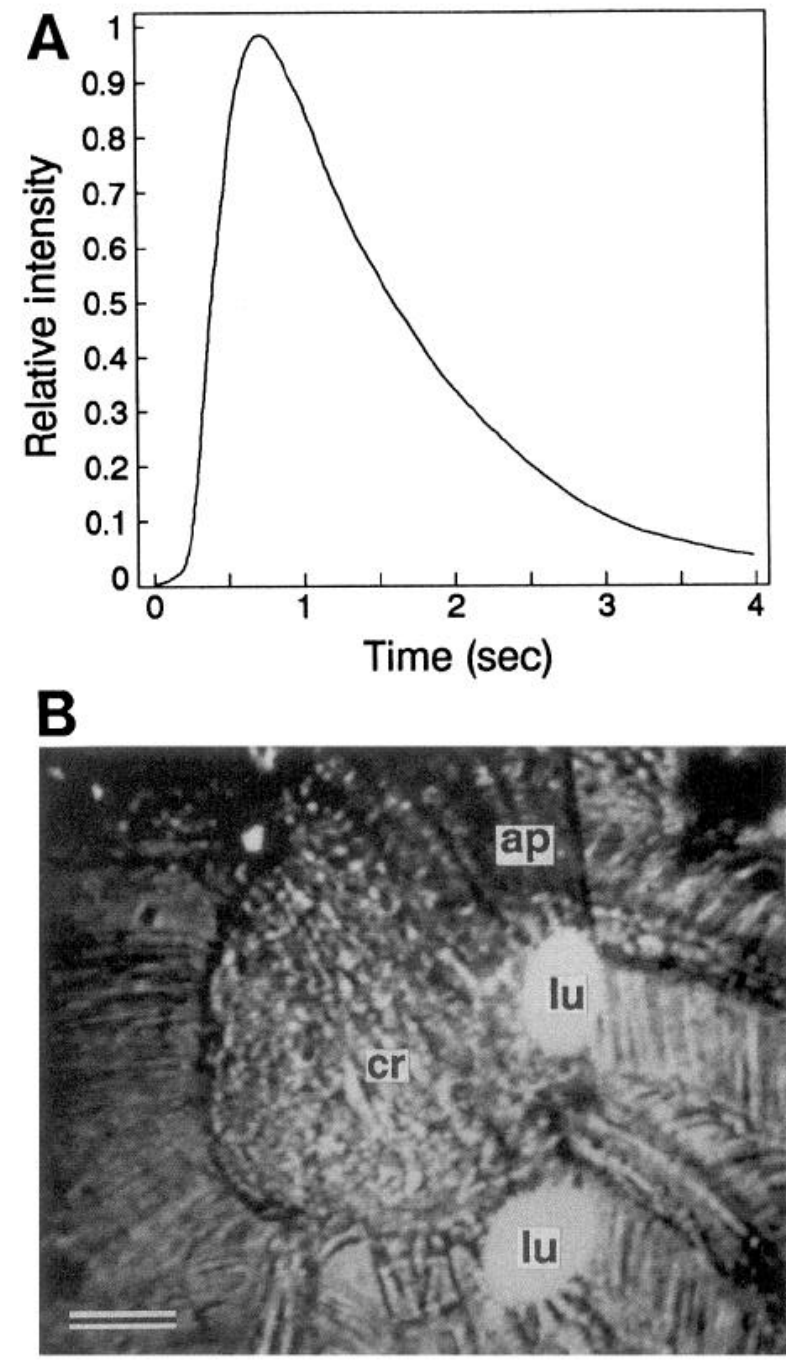

Figure 1. Bioluminescence produced by excised Gaussia princeps abdominal preparations. The ventral nerve cord at abdominal segment 1 was electrically stimulated with single $10-70 \mathrm{~V}$ square wave pulses. (A) Photomultiplier record of a slow flash. Mean flash latency is $109 \mathrm{~ms}$. (B) Image intensified video frame of the abdominal anal segment papilla and caudal rami luminous cells. Luminescence is produced exclusively external to the cuticle. Scale $=100 \mu \mathrm{m}$. ap, anal papilla; cr, caudal rami; lu, luminous secretion. 

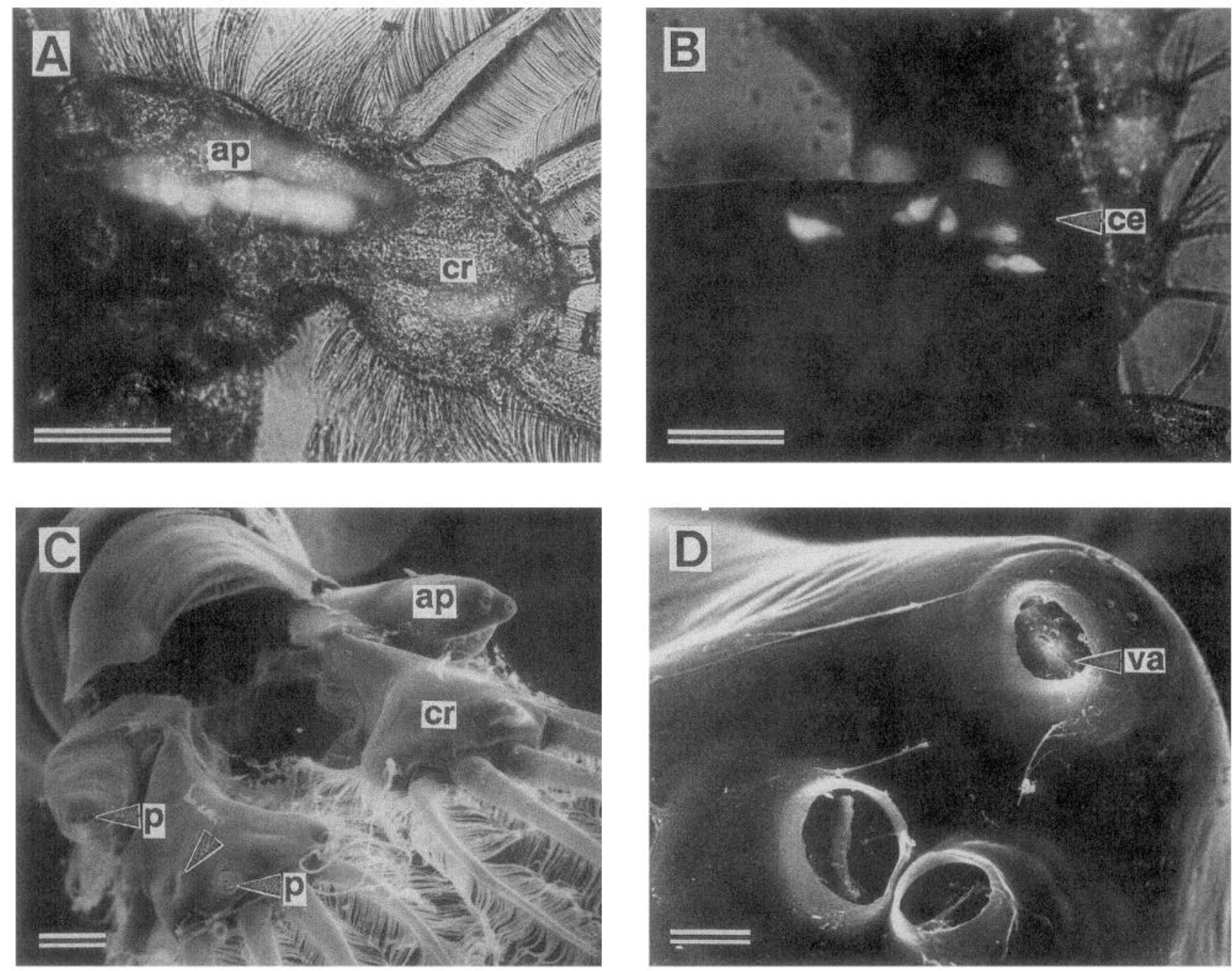

Figure 2. Structure of Gaussia princeps luminous glands. (A) Epifluorescence microscopy of luminous cells. The anal papilla and caudal rami each contain three luminous cells filled with fluorescent secretory vesicles. The third luminous cell is positioned below the visible cells. Scale $=300 \mu \mathrm{m}$. (B) Solitary fluorescent luminous cells located on the cephalothorax. Cells are much smaller than those of (A), with fewer secretory vesicles. Scale $=300 \mu \mathrm{m}$. (C) SEM of the abdominal anal papilla and caudal rami luminous cell cuticular pores (dorsal view). Each structure contains three cuticular pores. Pores not associated with fluorescent/ luminescent sites occur on the caudal rami (unlabeled arrowhead). Scale $=100 \mu \mathrm{m}$. (D) Luminous cell pores $(10 \mu \mathrm{m})$ of one anal papilla. Each pore contains a closed valve in the aperture. Valve shrinkage occurred in two of the three pores. Scale $=10 \mu \mathrm{m}$. ap, anal papilla; ce, cephalothorax; cr, caudal rami; p, pore; va, valve.

in $0.2 \mathrm{M}$ sodium phosphate buffer. Fixed material was rinsed and dehydrated through an increasing ethanol series. Specimens prepared for light microscopy and TEM were transferred into propylene oxide and infiltrated with increasing concentrations of Araldite or Spurr's resin over 3 days. Serial thick $(0.5-1 \mu \mathrm{m})$ and thin $(0.1 \mu \mathrm{m})$ transverse and longitudinal sections were cut on a Sorvall Porter-Blum ultramicrotome with glass knives for light microscopy and TEM. Light microscopy was performed using a Zeiss IM35 inverted microscope, while TEM was done on a Philips 300 . Following dehydration, specimens prepared for SEM were critical point dried, sputter coated with gold-palladium, and viewed with an Hitachi S-415A.

Whole-mount preparations of excised abdominal tissue were made by primary fixation in the presence of $0.1 \%$ methylene blue for $2 \mathrm{~h}$. Tissues were rinsed, dehydrated, and mounted on glass slides in Permount and examined with a Zeiss IM35 inverted microscope.

\section{Image intensification}

Low light level video images of luminescent activity in excised abdominal preparations were made with an ISIT 

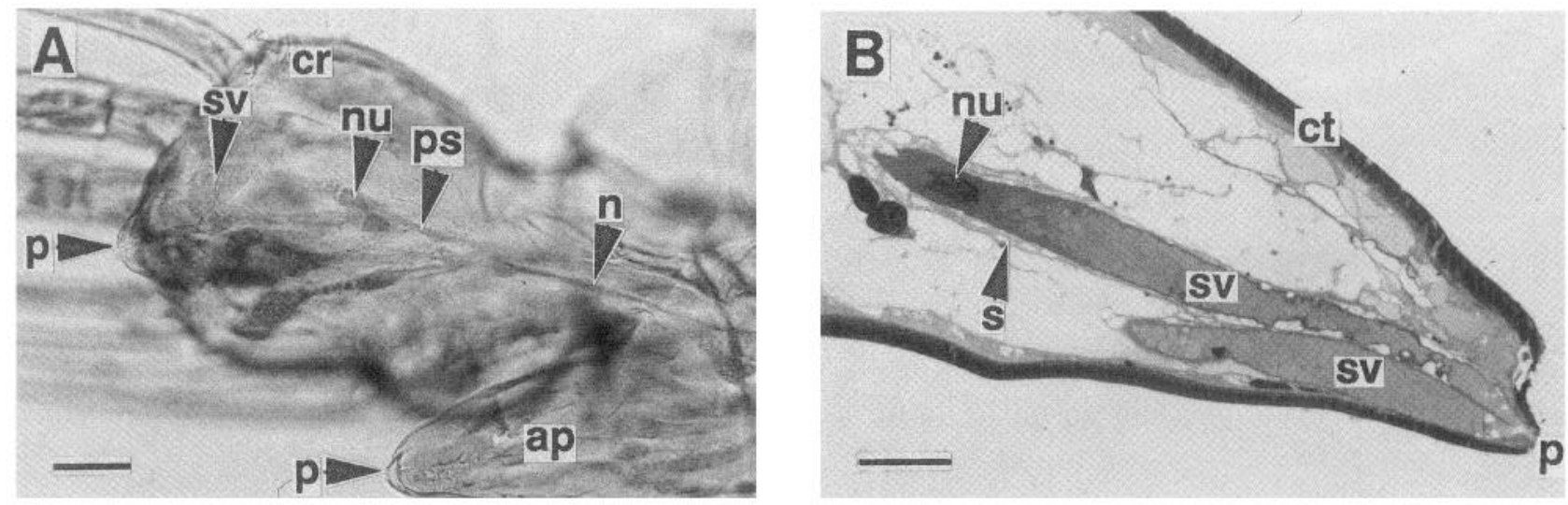

Figure 3. Light microscopy of abdominal luminous cell structure. Total luminous cell length is approximately $500 \mu \mathrm{m}$. (A) Abdominal whole mount stained with $0.1 \%$ methylene blue. Note the neural process terminating on the luminous cell proximal stem. Scale $=100 \mu \mathrm{m}$. (B) Longitudinal section through the anal papilla. Two luminous cells, filled with secretory vesicles and leading to separate cuticular pores, are shown. Luminous cell nucleus is located at the proximal border of the secretory vesicles. A sheath encloses the luminous cell. Scale $=50 \mu \mathrm{m}$. ap, anal papilla; ct, cuticle; cr, caudal rami; p, pore; ps, proximal stem; n, nerve; nu, nucleus; s, sheath; sv, secretory vesicles.

video camera, an F/0.95 lens, and a Zeiss IM35 inverted microscope. Video images were viewed at slow speed to analyze the luminescent patterns, and enhanced with a Megavision 1024XM image analysis system for final presentation. Bioluminescence was elicited using $50 \mathrm{~V}, 100$ ms square pulses delivered through tungsten glass insulated microelectrodes.

\section{Results}

\section{Physiology}

Focal electrical stimulation for $100 \mathrm{~ms}$ at $10 \mathrm{~V}$ near the ventral nerve cord of the bisected abdomen induced luminescence from the caudal rami and anal segment papillae. (Fig. 1A). Luminescence appeared predominantly as a slow flash with a mean duration of $3 \mathrm{~s}$ and a mean latency of $109 \mathrm{~ms}$. Nerve cord involvement was confirmed by stimulation at $70 \mathrm{~V}$ of adjacent longitudinal muscle groups without eliciting luminescence. Muscle tissues were also separated from the ventral nerve cord by longitudinal incisions from segments A1 to A3. Stimulation near the ventral nerve cord in such preparations continued to elicit luminescence, while muscle stimulation remained ineffective.

The excised abdomen produced luminescence only external to the cuticle (Fig. 1B). Light was never emitted intracellularly within luminous cells. Light appeared as a localized glow near the cuticular pores of the luminous cells. Details of excitation behavior in intact specimens are presented elsewhere (Bowlby and Case, in press).

\section{Luminous cell structure}

Epifluorescence microscopy revealed spherical, green fluorescent, secretory vesicles within each luminous cell
(Fig. 2A, B). Three cells occur in each anal segment papilla and caudal ramus (Fig. 2A), while solitary luminous cells occur in the cephalothorax (Fig. 2B), thorax, basal 8 antennule segments, and mandibular palps. Secretory vesicles were visually confirmed to be discharged through associated cuticular pores in several specimens. It was unclear if secretory vesicles were discharged intact or if secretion involved vesicle membrane lysis.

Three pores $(10 \mu \mathrm{m})$ are located on each anal papilla and caudal ramus (Fig. 2C) corresponding to discharge sites of the fluorescent secretory vesicles. Single pores are located near the fluorescent/luminescent sites on the thorax, cephalothorax, mandibular palps, and antennule segments. A closed valve-like structure is located in the aperture of each cuticular pore (Fig. 2D). Pore size and valve morphology were similar for luminous cells on the cephalothorax and thorax. Some valves appear as a partition dividing the pore aperture rather than as a valve, although it is suspected this is due to asymmetrical shrinkage of the valve away from the cuticle.

Abdominal luminous glands consist of a single long cell (approximately $500 \mu \mathrm{m}$ ), containing secretory vesicles distally, a nucleus at the proximal margin of the secretory vesicles, and a long stem proximal to the nucleus (Fig. $3 \mathrm{~A}, \mathrm{~B})$. Long nerve processes projecting from the midline of the specimen are associated with luminous cells (Fig. 3A).

Distal to the nucleus, large $(4 \mu \mathrm{m})$ secretory vesicles have amorphous contents (Fig. 4A, B). Endoplasmic reticulum and mitochondria closely surround the secretory vesicles. A cellular sheath surrounds all except the proximal end of the luminous cell (Figs. 3B; 4A, B). This sheath consists of layers of cells with clear cytoplasm, whose 

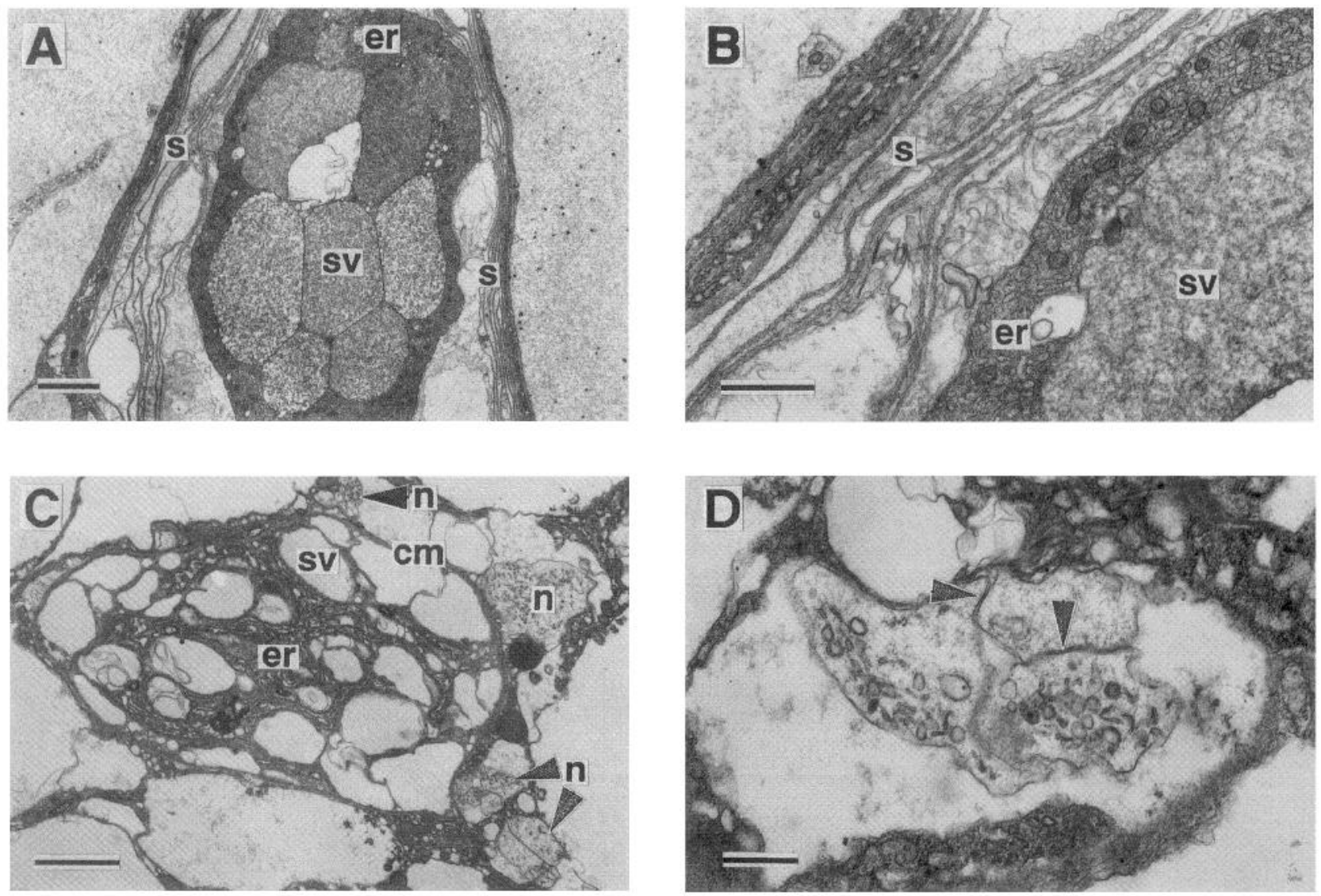

Figure 4. TEM of luminous cells. (A) Transverse section of an abdominal luminous cell distal to the nucleus. Secretory vesicles $(4 \mu \mathrm{m})$, containing an amorphous material, are surrounded by endoplasmic reticulum. Scale $=2 \mu \mathrm{m}$. (B) Transverse section of the peripheral components of the luminous cell. The luminous cell is surrounded by a sheath consisting of layers of thin cells. Note mitochondria within the endoplasmic reticulum. Scale $=1 \mu \mathrm{m}$. (C) Proximal stem near the proximal limit of the luminous cell, containing endoplasmic reticulum and $2 \mu \mathrm{m}$ electron-lucent precursors to secretory vesicles, but no cellular sheath. Nerve terminals filled with synaptic vesicles are associated with the luminous cell membrane. Scale $=3 \mu \mathrm{m}$. (D) Nerve terminals containing $110 \mathrm{~nm}$ synaptic vesicles and interconnected by $5 \mathrm{~nm}$ gap junctions (arrowheads). Scale $=0.5 \mu \mathrm{m}$. cm, cell membrane; er, endoplasmic reticulum; n, nerve; s, sheath; sv, secretory vesicles.

membranes are separated by a thin extracellular space containing fibrous material (Fig. 4B).

The proximal limit of the luminous cell consists of endoplasmic reticulum and smaller $(2 \mu \mathrm{m})$ electron-lucent precursors to secretory vesicles, but no cellular sheath (Fig. 4C). Nerves are associated only with this region of the luminous cell. Nerves often contain large light and dense staining synaptic vesicles, and appear in close association with the cell membrane (Fig. 4C, D). Synaptic vesicles are either ovoid (mean largest diameter $=97 \mathrm{~nm}$ ) or spherical $($ mean diameter $=116 \mathrm{~nm})$. Nerve cells are interconnected in several locations by $5 \mathrm{~nm}$ gap junctions (Fig. 4D).

A composite drawing of a hypothetical Gaussia princeps luminous cell indicates the predominance of secretory vesicles in the distal region (Fig. 5). Secretory vesicles are expelled through a valve in the pore, which have been observed open or closed in other genera (Herring, 1988; Bannister and Herring, 1989). The valve appears to be formed from the sheath, which surrounds all except the proximal region of the luminous cell. Nerve terminals, filled with synaptic vesicles, are associated with the proximal, unsheathed portion of the cell.

\section{Discussion}

Luminescence in Gaussia princeps occurs by expulsion of secretory vesicles through a cuticular pore. The luminescent process presumably involves at least three steps: (1) neural activation of the luminous cell, (2) expulsion of secretory vesicles through cuticular pores, culminating in (3) initiation of swimming movements and displace- 


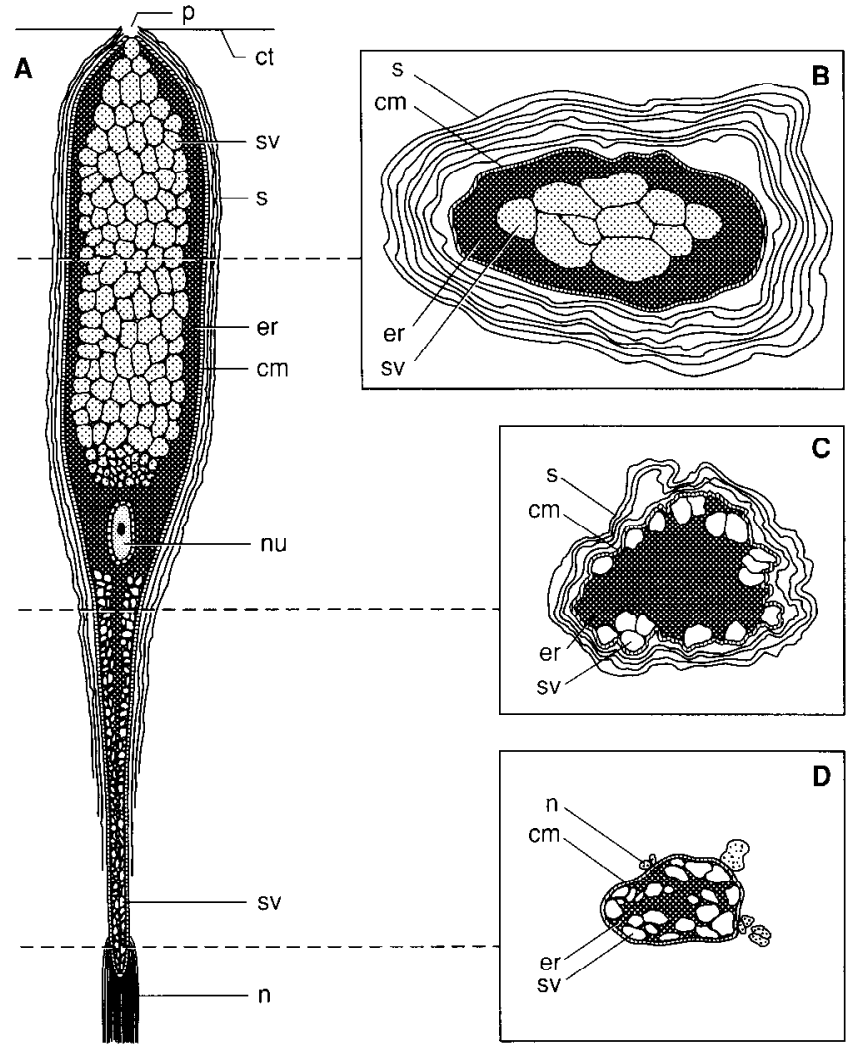

Figure 5. Gaussia princeps. Diagrammatic illustration of a luminous cell. (A) Longitudinal view of all portions of the cell. (B) Transverse view of the secretory vesicle containing portion of the cell. (C) and (D) Transverse views of the proximal stem. $\mathrm{cm}$, cell membrane; ct, cuticle; er, endoplasmic reticulum; $n$, nerves; nu, nucleus; $p$, pore; s, sheath; sv, secretory vesicles.

ment of the animal away from the persistently luminous bolus.

Luminous cells consist largely of secretory vesicles contained within an endoplasmic reticulum matrix. Precursors to secretory vesicles may be produced in the proximal stem of the luminous cell and transported to the distal region of the cell, where they fuse and acquire amorphous material, forming large secretory vesicles. The single luminous cell type of $G$. princeps appears similar to those in other members of the Metridinidae (Herring, 1988; Bannister and Herring, 1989). Pleuromamma xiphias and Metridia princeps have luminous cells filled distally with secretory vesicles and enclosed within a sheath. In the Augaptilidae, in contrast, a pair of luminous cells discharge through a common pore (Bannister and Herring, 1989). Secretory vesicles are morphologically very different from the Metridinidae, containing paracrystalline contents.

Fluorescence from the secretory vesicles indicates the probable presence of luciferin or its precursors. In the absence of a second type of differentially staining intra- cellular organelles, the secretory vesicles also presumably contain, or have associated with them, luciferase. The absence of necessary cofactor(s) such as oxygen, ATP, $\mathrm{Ca}^{+2}$, $\mathrm{Mg}^{+2}$, or $\mathrm{Cu}^{+2}$ (Campbell, 1988, 1989), may prevent luminescence from being expressed within the luminous cell. Many of these cofactor(s) are likely to be present in the seawater, and thus could initiate light generation once expulsion occurs. The slow decay of light when secretory vesicles are not dispersed by appendage movement may result from the slow diffusion of cofactor(s) into the bolus of secreted material. Similarly, luminescence induced by mechanical pressure on a light gland may be due to ruptures of the luminous cell and cuticle, allowing entry of seawater and cofactor(s) into the gland (Barnes and Case, 1972; Bannister and Herring, 1989). Alternatively, changes in permeability or breakdown of vesicular bounding membrane upon excretion may permit the luminescence reaction to proceed.

Neuroeffector junctions occur only on the proximal region of the luminous cell. While classical membrane active zones were not found, large synaptic vesicles fill the terminals. Gap junctions among peripheral nerves may serve to ephaptically accelerate conduction to the luminous cell and achieve simultaneous effector output. The mechanism of material expulsion from the luminous cells cannot be related to the action of muscle fibers or microfilaments, due to their absence near the cells (Herring, 1988; Bannister and Herring, 1989; present study). Because luminous expulsion occurs from excised abdomens, changes in coelomic hydrostatic pressure are also not responsible for the expulsion process. Release of neurotransmitter from the ncurocffector junction synaptic vesicles in response to neural stimulation is assumed to cause changes in luminous cell membrane conductance, leading to ionic changes within the cell and luminescent vesicle release to the exterior.

Electrically induced flashes from excised abdominal preparations were predominantly of the slow flash type described in Bowlby and Case (in press). The latent period, however, is 10 times shorter in excised tissue than in intact specimens. This difference may be due to the absence of receptor delay, central nervous system processing, and to a shorter final motor pathway. The absence of the other flash types in excised preparations is not due to incapacity on the part of the abdominal photocytes, as they produce fast, long, and compound responses in intact specimens. Rather, we suspect that central nervous system temporal patterning of command motor impulses may regulate flash patterns.

Copepods generally live under conditions of high kinematic viscosity and low Reynolds numbers (Vogel, 1981). The ejection of luminous material beyond the boundary layer of the integument presents a problem under these conditions. Experiments with scale copepod 
models in flow tanks indicate that an artificial secretion of a short pressure pulse produces a torus of secretory product that escapes from the boundary layer (Herring, 1988). Luminous cells in excised $G$. princeps abdomens were able to eject luminescent material beyond the cuticular boundary layer. Thus luminescent material is apparently secreted from the abdominal luminous cells as a short pressure pulse. Intact specimens also commonly flex the abdomen and burst/escape swim to further eject luminous material and displace themselves from the luminous secretion (Bowlby and Case, in press).

\section{Acknowledgments}

The authors wish to thank the captains and crews of the R. V. New Horizon and R. V. Point Sur. J. Childress generously provided ship time, and M. Latz, A. Grutter, and K. Linberg provided technical assistance. Supported by the Office of Naval Research (Contracts N00014-84K-0314 and N00014-87-K-0044).

\section{Literature Cited}

Anctil, M., and J. F. Case. 1977. The caudal luminous organs of lantern fishes: general innervation and ultrastructure. Am. J. Anat. 149: 122.

Anderson, P. A. V., and J. F. Case. 1975. Electrical activity associated with luminescence and other colonial behavior in the pennatulid Renilla kollikeria. Biol. Bull. 149: 80-95.

Baguet, F., and J. Case. 1971. Luminescent control in Porichthys (Teleostei): excitation of isolated photophores. Biol. Bull. 140: 15-27.

Bannister, N. J., and P. J. Herring. 1989. Distribution and structure of luminous cells in four marine copepods. J. Mar. Biol. Assoc. UK 69: $523-533$.

Barnes, A. T., and J. F. Case. 1972. Bioluminescence in the mesopelagic copepod, Gaussia princeps (T. Scott). J. Exp. Mar. Biol. Ecol. 8: 5371.

Bassot, J. M., A. Bilbaut, G. O. Mackie, L. M. Passano, and M. Pavans De Ceccatty. 1978. Bioluminescence and other responses spread by epithelial conduction in the siphonophore Hippopodius. Biol. Bull. 155: 473-479.

Bowlby, M. R., and J. F. Case. 1989. Endogenous bioluminescent characteristics of a mesopelagic copepod. Am. Zool. 29: 37A. (Abstract)

Bowlby, M. R., and J. F. Case. in press. Flash kinetics and spatial patterns of bioluminescence in the copepod Gaussia princeps. Mar. Biol.
Brehm, P. 1977. Electrophysiology and luminescence of an ophiuroid radial nerve. J. Exp. Biol. 71: 213-227.

Buck, J., and J. F. Case. 1961. Control of flashing in fireflies. I. The lantern as a neuroeffector organ. Biol. Bull. 121: 234-256.

Campbell, A. K. 1988. Chemiluminescence: Principles and Application in Biology and Medicine. VCH/Horwood, Chichester.

Campbell, A. K. 1989. Living light: biochemistry, function and biomedical applications. Essays Biochem. (Biochemical Soc., Lond.) 24: 41-81.

Case, J. F., and J. Buck. 1963. Control of flashing in fireflies. II. Role of central nervous system. Biol. Bull. 125: 234-250.

Case, J. F., and L. G. Strause. 1978. Neurally controlled luminescent systems. Pp. 331-366 in Bioluminescence in Action. P. J. Herring, ed. Academic Press, New York.

Childress, J. J. 1977. Effects of pressure, temperature and oxygen on the oxygen-consumption rate of the midwater copepod Gaussia princeps. Mar. Biol. 39: 19-24.

Childress, J. J., A. T. Barnes, L. B. Quetin, and B. H. Robison. 1978. Thermally protecting cod ends for the recovery of living deepsea animals. Deep-Sea Res. 25: 419-422.

Clarke, G. L., R. Conover, C. David, and J. Nicol. 1962. Comparative studies of luminescence in copepods and other pelagic marine animals. J. Mar. Biol. Assoc. UK 42: 541-564.

Dennell, R. 1940. On the structure of the photophores of some decapod Crustacea. Discovery Rep. 20: 307-382.

Harvey, E. N. 1952. Rioluminescence. Academic Press, New York.

Herrera, A. A. 1977. The physiology of bioluminescence in polynoid worms. Ph.D. Dissertation, University of California, Los Angeles.

Herring, P. J. 1988. Copepod luminescence. Hydrobiologia 167/168: 183-195.

Kay, R. H. 1965. Light-stimulated and light-inhibited bioluminescence of the euphausid Meganyctiphanes norvegica (G. O. Sars). Proc. $R$. Soc. Lond. (B) 162: 365-386.

Kay, R.H. 1966. The inhibition of optically stimulated bioluminescence in Meganyctiphanes norvegica. George Allen and Unwin Ltd., London.

Latz, M. I., M. R. Bowlby, and J. F. Case. 1990. Recovery and stimulation of copepod bioluminescence. J. Exp. Mar. Biol. Ecol. 136: $1-22$.

Latz, M. I., T. M. Frank, M. R. Bowlby, E. A. Widder, and J. F. Case. 1987. Variability in flash characteristics of a bioluminescent copepod. Biol. Bull. 173: 489-503.

Linberg, K., and J. F. Case. 1982. Comparative ultrastructure of adult light organs in synchronously and asynchronously flashing fireflies. MA. Thesis, University of California, Santa Barbara.

Nicol, J. A. C. 1967. The luminescence of fish. Symp. Zool. Soc. Lond. 19: $27-55$.

Smith, D.S. 1963. The organization and innervation of the luminescent organ in a firefly, Photuris pennsylvanica (Coleoptera). J. Cell Biol. 16: 323-359.

Vogel, S. 1981. Life in Moving Fluids. The University Press, Princeton, NJ. 